\title{
RESEARCH
}

\section{Thyroid dysfunction and cancer incidence: a systematic review and meta-analysis}

\author{
Thi-Van-Trinh Tran'1, Cari M Kitahara², Florent de Vathaire ${ }^{1}$, Marie-Christine Boutron-Ruault ${ }^{3}$ and Neige Journy ${ }^{1}$ \\ ${ }^{1}$ Cancer and Radiation Group, Center for Research in Epidemiology and Population Health, INSERM U1018, Paris Sud-Paris Saclay University, \\ Gustave Roussy, Villejuif, France \\ ${ }^{2}$ Radiation Epidemiology Branch, Division of Cancer Epidemiology and Genetics, National Cancer Institute, National Institutes of Health, Bethesda, \\ Maryland, USA \\ ${ }^{3}$ Health Across Generations Group, Center for Research in Epidemiology and Population Health, INSERM U1018, Paris Sud-Paris Saclay University, \\ Gustave Roussy, Villejuif, France
}

Correspondence should be addressed to T-V-T Tran: Thivantrinh.TRAN@gustaveroussy.fr

\begin{abstract}
In this study, we aimed to evaluate site-specific cancer risks associated with hyperthyroidism or hypothyroidism. We performed a systematic review of observational studies reporting associations between hyperthyroidism or hypothyroidism and subsequent site-specific cancer incidence, in MEDLINE and the COCHRANE library (inception-28/01/2019) (PROSPERO: CRD42019125094). We excluded studies with thyroid dysfunction evaluated as a cancer biomarker or after prior cancer diagnosis and those considering transient thyroid dysfunction during pregnancy or severe illnesses. Risk of bias was assessed using a modified Newcastle-Ottawa scale. Risk estimates were pooled using random-effects models when $\geq 5$ studies reported data for a specific cancer site. Twenty studies were included, of which 15 contributed to the meta-analysis. Compared to euthyroidism, hyperthyroidism was associated with higher risks of thyroid (pooled risk ratio: $4.49,95 \% \mathrm{Cl}: 2.84-7.12$ ), breast (pooled risk ratio: $1.20,95 \% \mathrm{Cl}: 1.04-1.38$ ), and prostate (pooled risk ratio: $1.35,95 \% \mathrm{Cl}: 1.05-1.74$ ), but not respiratory tract (pooled risk ratio: 1.06, 95\% Cl: 0.80-1.42) cancers. Hypothyroidism was associated with a higher risk of thyroid cancer within the first 10 years of follow-up only (pooled risk ratio: 3.31, $95 \% \mathrm{Cl}: 1.20-9.13)$. There was no or limited evidence of thyroid dysfunction-related risks of other cancer sites. In conclusion, thyroid dysfunction was associated with increased risks of thyroid, breast, and prostate cancers. However, it remains unclear whether these findings represent causal relationships because information on treatments and potential confounders was frequently lacking.
\end{abstract}

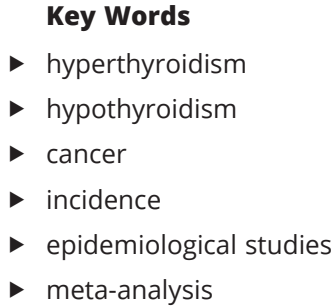

Endocrine-Related Cancer (2020) 27, 245-259

\section{Introduction}

Thyroid dysfunction can present as decreased (hyperthyroidism) or elevated (hypothyroidism) thyroidstimulating hormone (TSH) serum levels, leading to an increased or decreased production of thyroid hormones (triiodothyronine (T3) and/or thyroxin (T4)), respectively. Autoimmune conditions, such as Graves' disease (hyperthyroidism) and Hashimoto's thyroiditis (hypothyroidism), are the most common causes of thyroid dysfunction in iodine-replete areas. Thyroid dysfunction can occur in both sexes, but is particularly frequent (c) 2020 Society for Endocrinology Published by Bioscientifica Ltd. Printed in Great Britain 
among women aged 40 years and older, with a prevalence of $5-15 \%$ in iodine-replete communities (Garmendia Madariaga et al. 2014, Journy et al. 2017).

Thyroid dysfunction may be involved in carcinogenesis. Thyroid hormones and TSH can directly enhance tumor proliferation through their cell surface receptors, estrogen pathways, increased angiogenesis, and gene expression regulation (Moeller \& Führer 2013, Hercbergs et al. 2018). Moreover, thyroid dysfunction is associated with obesity (Laurberg et al. 2012), diabetes mellitus (Brandt et al. 2013), and vascular diseases (Brandt et al. 2013), which have been linked to an increased cancer risk or shared common risk factors. However, epidemiological evidence on the association between thyroid dysfunction and cancer risk has been contradictory. Several studies have reported increased risks of thyroid or breast cancer associated with hyperthyroidism and decreased or unchanged risks with hypothyroidism, compared to euthyroid individuals (Cristofanilli et al. 2005, Balasubramaniam et al. 2012, Søgaard et al. 2016, Kitahara et al. 2018). However, in some other large cohorts, there was no association between thyroid dysfunction and cancer risk (Metso et al. 2007, Hellevik et al. 2009). Four previous meta-analyses on breast cancer found no significantly increased or decreased risks with thyroid dysfunction, but highlighted the heterogeneity of results across studies published from 2002 to 2016 (Sarlis et al. 2002, Angelousi et al. 2012, Hardefeldt et al. 2012, Fang et al. 2017). A pooled analysis of case-control studies published in 1984-1997 showed an increased risk of thyroid cancer with selfreported hyperthyroidism, but not with hypothyroidism (Franceschi et al. 1999). Interpretation of these results is nevertheless hampered by several factors: lack of longitudinal studies, lack of data on thyroid dysfunction treatments, inclusion of prevalent cancer cases, and the possibility of reverse causality. Recently, two additional large studies have provided new evidence of an elevated risk of thyroid cancer in relation to thyroid dysfunction (Huang et al. 2017, Kitahara et al. 2018). Other studies reported associations with other cancer sites, such as prostate and lung (Mellemgaard et al. 1998, Hellevik et al. 2009), which have not yet been analyzed in a systematic review or meta-analysis.

In this systematic review and meta-analysis, we comprehensively summarized the published evidence up to 2019 on the associations of hyperthyroidism and hypothyroidism with site-specific cancer incidence. We also reported the current evidence on cancer risks associated with thyroid dysfunction treatments.

\section{Materials and methods}

This study was conducted in accordance with the Preferred Reporting Items for Systematic Reviews and Meta-Analyses (PRISMA) guidelines (Moher et al. 2009) (Supplementary Appendix 1, see section on supplementary materials given at the end of this article). Our protocol was registered in the PROSPERO International prospective register of systematic reviews database (CRD42019125094) prior to study.

\section{Search strategy}

We performed a systematic literature search in PubMed/MEDLINE and the Cochrane library from inception to January 28, 2019. We included case-control and cohort studies that reported a measure of association between thyroid dysfunction (overt and subclinical) or thyroid hormone levels compatible with thyroid dysfunction diagnosed before cancer diagnosis (Box 1) and subsequent site-specific cancer risk. Our search strategy included MeSH terms and key words in the titles and abstracts (Supplementary Appendix 2). We restricted the search to English, French and Vietnamese languages, and to studies in humans. Reference lists of eligible articles and previous systematic reviews (Franceschi et al. 1999, Sarlis et al. 2002, Angelousi et al. 2012, Hardefeldt et al. 2012, Fang et al. 2017) were hand searched to identify additional relevant studies.

\section{Study selection}

One investigator (T V T T) screened the title and abstract of all articles identified in the initial search and reviewed

\section{Box 1. Definition of hyperthyroidism and hypothyroidism used in the search.}

- Overt or subclinical hyperthyroidism and hypothyroidism, reported in medical or laboratory records, questionnaires, registry or medico-administrative databases, or measured in blood samples, prior to cancer diagnosis. People with Graves' disease, toxic nodular goiter, and thyrotoxicosis were considered as hyperthyroid and those with Hashimoto's disease as hypothyroid.

- Thyroid-stimulating hormone (TSH), free thyroxine (FT4) and/or free triiodothyronine (FT3) levels beyond reference levels in iodine-replete populations: TSH 0.4-4.0 mIU/L, FT4 9-25 pmol/L (0.7-1.9 ng/dL), and FT3 $3.5-7.8 \mathrm{nmol} / \mathrm{L}(0.2-0.5 \mathrm{ng} / \mathrm{dL})$. When possible, overt and subclinical thyroid dysfunction was differentiated, as defined in Supplementary Appendix 5. (c) 2020 Society for Endocrinology Published by Bioscientifica Ltd. Printed in Great Britain 
the full text of potentially eligible articles. Our exclusion criteria were (1) hyperthyroidism and hypothyroidism not reported separately, (2) no information on specific cancer sites, (3) no reported measure of association between hyperthyroidism or hypothyroidism and cancer incidence, (4) thyroid dysfunction evaluated as a cancer biomarker (e.g. thyroid cancer), (5) thyroid dysfunction evaluated after cancer diagnosis or no/limited information on cancer history prior to thyroid dysfunction evaluation, (6) participants with a prior malignant condition or treated cancer, and (7) transient thyroid dysfunction during pregnancy or severe illnesses. Because thyroid dysfunction can also affect cancer survival (Sandhu et al. 2009, Minlikeeva et al. 2017), possibly through early or delayed cancer detection due to the management of thyroid function or associated comorbidities (e.g. diabetes, cardiovascular diseases) or differences in cancer treatment strategies due to the presence of comorbidities (Sarfati et al. 2016), it is difficult to disentangle the effects of thyroid dysfunction on cancer incidence and survival.
Consequently, we disregarded studies on cancer mortality, of which only two (Goldman et al. 1988, Journy et al. 2017) excluded individuals with prior cancer history at thyroid dysfunction assessment (exclusion criterion \#5; Fig. 1, Supplementary Appendix 6).

\section{Data extraction}

Using pre-defined data extraction forms, two investigators ( T V T T and $\mathrm{N} \mathrm{J}$ ) independently extracted the following information from the included studies: study setting and design, sample size, follow-up methods and duration, participant characteristics (age, sex, and menopausal status), thyroid dysfunction (definition, ascertainment methods, and treatments), cancer outcomes (definition and ascertainment methods), methods for statistical analysis (risk modelling and adjustment variables), and multivariable analysis results, including cases, controls number, and risk estimates. We retrieved data from the most informative studies in case of duplicate data sources.

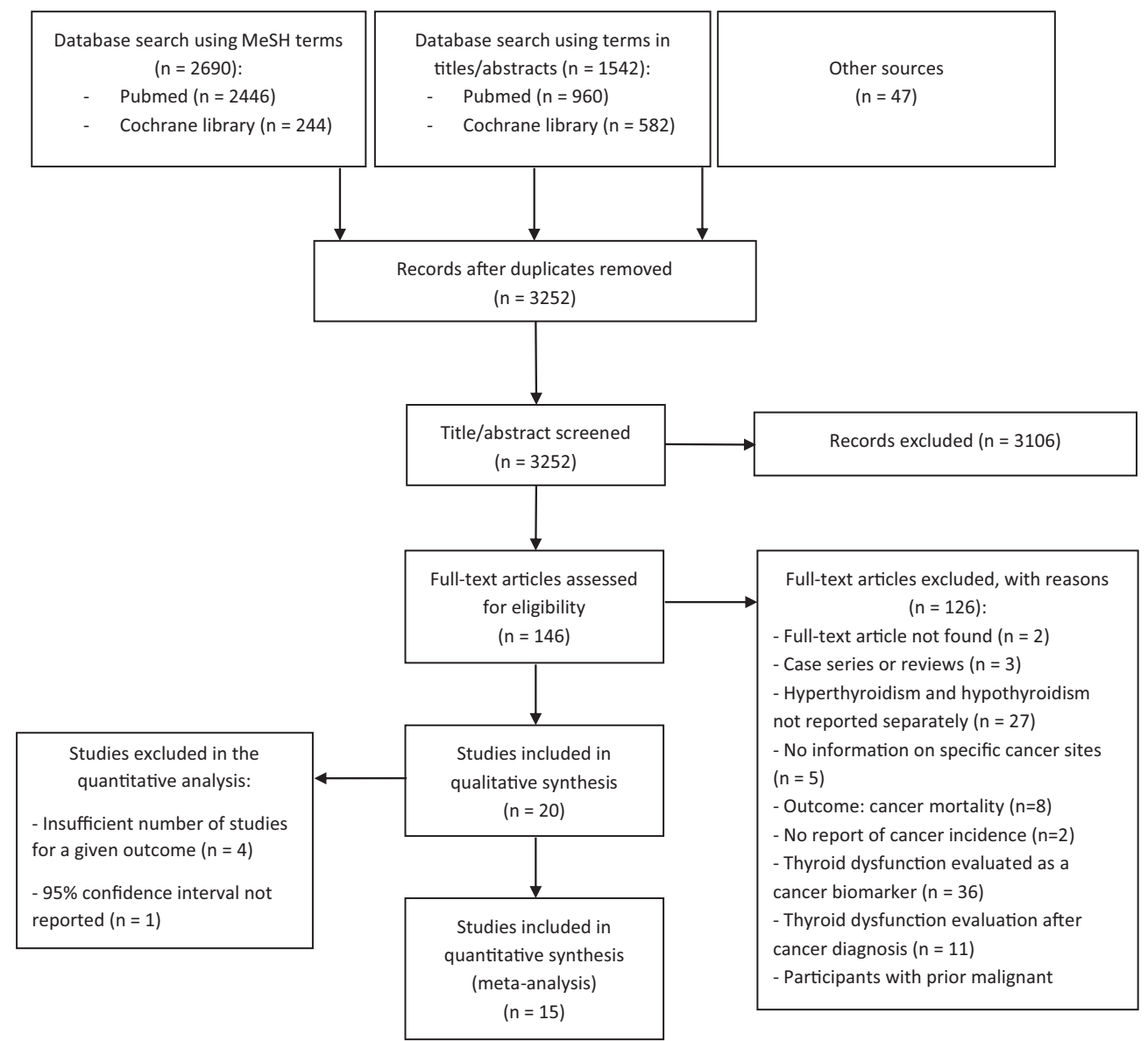

Figure 1

PRISMA flow diagram outlining search strategy and the final included and excluded studies.

(c) 2020 Society for Endocrinology Published by Bioscientifica Ltd. Printed in Great Britain 
Previous reports of the study population were reviewed for additional information that was not available in the included article. Corresponding authors were contacted when necessary.

\section{Quality assessment}

Two investigators (T V T T and N J) independently assessed risk of bias of the included studies, in terms of participant selection, comparability of groups, and ascertainment of the outcome (in cohorts) or exposure (in case-control studies), using a modified Newcastle-Ottawa scale (NOS) (Wells 2001) (Supplementary Appendix 3). This scale contains a number of items (selection: $n=4$, comparability: $n=2$, outcome: $n=3$, and exposure: $n=5$ ), to which a point was awarded to modalities with the lowest risk of bias. To date, no consensus has been reached on the interpretation of assigned points to NOS items. Therefore, we arbitrarily considered $\geq 2, \geq 1, \geq 2$, and $\geq 3$ points as 'low-to-moderate' risk of bias for selection, comparability, outcome, and exposure domains, respectively (Supplementary Appendix 4). In studies investigating several outcomes, the risk of bias could vary according to the cancer of interest. Inconsistent ratings between the two investigators were resolved by discussion.

\section{Statistical analysis}

For each study, we extracted risk estimates (relative risk, odds ratio, hazard ratio, or standardized incidence ratio) adjusted for the most covariables and 95\% CIs from the original article. We pooled risk ratios when associations of hyperthyroidism or hypothyroidism and site-specific cancer incidence were reported in five studies or more. Estimates for respiratory tract cancers were combined with those for lung cancer only, which accounts for more than 90\% of the former category (Forman et al. 2013). Pooled risk ratios were estimated using DerSimonian and Laird random-effect models (DerSimonian \& Laird 1986). In sensitivity analyses, we compared our results with those using fixed-effect models. For studies which reported only sex-specific risk ratios, these risk estimates were pooled using a fixed-effect model in order to have a single risk ratio per study.

Heterogeneity across studies was evaluated using the Q-statistic with a conservative $10 \% P$-value because it has low power (Petitti 2001) and the $\mathrm{I}^{2}$ statistic (Higgins \& Thompson 2002), which represents the proportion of total variance of a pooled risk ratio attributable to variability across studies. An $\mathrm{I}^{2}$ value greater than

(c) 2020 Society for Endocrinology Published by Bioscientifica Ltd. Printed in Great Britain
$50 \%$ indicates a substantial heterogeneity level. To explore the heterogeneity sources, we conducted analyses stratified by thyroid dysfunction treatments: no treatment, radioactive iodine (RAI) only, thyroid hormone replacement therapy (THRT) only, mixed modalities, or unspecified treatments. No studies have investigated surgery and antithyroid drugs as a unique treatment of thyroid dysfunction. Except for the study of Goldman et al. (1988) which had some follow-up data, we analyzed only treatments ascertained at study inclusion due to the unavailability of follow-up data in all other cohort studies. Furthermore, we estimated pooled risk ratios stratified by sex (men or women), methods for thyroid dysfunction ascertainment (in-/out-patient hospital diagnoses, or others), study design (cohort or case-control), and geographic region (Asia, Australia, Europe, or North America). We also used the Q-statistic to test for subgroup differences - with $P$-values $<0.1$ indicating evidence of heterogeneity. Other sensitivity analyses were restricted to studies with low-to-moderate risk of bias for each NOS domain or those with a minimum follow-up time of 1 year to minimize the probability of reverse causation (i.e. thyroid dysfunction due to cancer). We conducted an influence analysis by the leave-one-out method to assess whether the pooled risk estimates were driven by specific studies (Viechtbauer \& Cheung 2010).

To further explore the possibility of reverse causation, we estimated pooled risk ratios as a function of time, since thyroid dysfunction diagnosis/detection in a metaregression analysis (Thompson \& Higgins 2002), among studies reporting risk ratios for at least two follow-up time categories. Only studies on thyroid cancer risk fulfilled this requirement. For each category, follow-up time was assigned as the midpoint between the upper and the lower bound. For open-ended upper categories, we applied the range of the previous category. We modeled the log (risk ratio) as a linear or non-linear function of follow-up time. Departure from linearity was assessed by testing the statistical significance of second and third degree polynomials terms and restricted cubic splines with four knots at $0.05,0.35,0.65$, and 0.95 percentiles.

Publication bias was assessed by Egger tests and funnel plots (Egger et al. 1997). The analyses were performed in $\mathrm{R}$ version 3.5.3 (https://www.R-project.org/) using the 'meta' and 'metafor' packages.

\section{Results}

After screening the title and abstract of 3252 nonduplicated articles and reviewing the full text of 
146 potentially eligible articles, we included 20 studies (12 cohort and 8 case-control studies) in the literature synthesis (Fig. 1). Of these, 15 studies contributed to the meta-analysis for thyroid $(n=8)$, breast $(n=9)$, prostate $(n=6)$, and respiratory tract $(n=7)$ cancers.

\section{Study characteristics}

Studies were conducted in Europe $(n=6)$, the USA $(n=9)$, Taiwan $(n=3)$, Kuwait $(n=1)$, and Australia $(n=1)$. Thirteen studies were population-based (Mellemgaard et al. 1998, Memon et al. 2002, Welzel et al. 2007, Hellevik et al. 2009, Balasubramaniam et al. 2012, Chen et al. 2013a,b, Kang et al. 2013, Yeh et al. 2013, Chan et al. 2017, Huang et al. 2017, Petrick et al. 2017, Kitahara et al. 2018), of which five were nationwide (Mellemgaard et al. 1998, Chen et al. 2013a,b, Kitahara et al. 2018) or nationally representative (Yeh et al. 2013), where thyroid dysfunction was assessed through in- and/or out-patient hospital databases (Table 1). Three population-based studies had information on serum TSH and/or thyroid hormones concentrations (Hassan et al. 2009, Hellevik et al. 2009, Chan et al. 2017). Differences in study design resulted in widely variable sample size (ranging from 342 to 4.5 million) and mean/median follow-up time (ranging from 6 to 17 years on average; not reported for 13 studies). Fourteen studies included both females (proportion: 39\% to $90 \%$ ) and males. In cohort studies, the prevalence of hyperthyroidism and hypothyroidism ranged respectively from $0.3 \%$ to $2.5 \%$ and $0.6 \%$ to $7.8 \%$ across cohorts, respectively (mean age at thyroid dysfunction assessment: 40 to 62 years). Treatment modalities of thyroid dysfunction were: RAI only (Metso et al. 2007), THRT only (Cristofanilli et al. 2005), mixed modalities (Munoz et al. 1978, Goldman et al. 1988, Kang et al. 2013), no treatment (Hellevik et al. 2009, Yeh et al. 2013, Chan et al. 2017), or unspecified (Talamini et al. 1997, Mellemgaard et al. 1998, Memon et al. 2002, Welzel et al. 2007, Hassan et al. 2009, Balasubramaniam et al. 2012, Mondul et al. 2012, Chen et al. 2013a,b, Huang et al. 2017, Petrick et al. 2017, Kitahara et al. 2018). Treatments were ascertained at study inclusion, since there was incomplete (Goldman et al. 1988) or no follow-up data in the original studies. Diabetes and overweight/obesity were the most commonly reported comorbidities, with a prevalence of $2-10 \%$ in cohorts and $10-46 \%$ in case-control studies. Overall, nine (45\%) studies were considered as moderate-to-low risk of bias (Supplementary Appendix 4). Neither the funnel plots nor the Egger's test showed evidence of publication bias for any outcome (Supplementary Figs 1, 2, 3, 4, 5 and 6).

\section{Thyroid cancer}

Seven (Memon et al. 2002, Metso et al. 2007, Yeh et al. 2013, Balasubramaniam et al. 2012, Chen et al. 2013a, Huang et al. 2017, Kitahara et al. 2018) and five (Memon et al. 2002, Balasubramaniam et al. 2012, Chen et al. 2013b, Huang et al. 2017, Kitahara et al. 2018) studies reported risks associated with hyperthyroidism and hypothyroidism, respectively, with a total sample size of 12.9 million individuals. They consistently reported increased risks for both hyperthyroidism and hypothyroidism, reaching statistical significance in studies with the largest numbers of cases (Figs 2 and 3). Most studies regarding hyperthyroidism (Memon et al. 2002, Chen et al. 2013a, Yeh et al. 2013, Huang et al. 2017, Kitahara et al. 2018) and hypothyroidism (Memon et al. 2002, Chen et al. 2013b, Huang et al. 2017, Kitahara et al. 2018) had low-to-moderate risks of bias for the selection and outcome/exposure domains, but adjustment for potential confounding factors, particularly calendar year, BMI, diabetes, and reproductive factors, was lacking in some studies (Memon et al. 2002, Metso et al. 2007, Chen et al. 2013a,b). The pooled risk ratio was 4.49 (95\%CI 2.83 to $7.12,280$ cases among the exposed) for hyperthyroidism and 3.31 (95\%CI 1.20 to $9.13,171$ cases among the exposed) for hypothyroidism. However, there was a substantial evidence for heterogeneity in both analyses $\left(\mathrm{I}^{2}>80 \%, P<0.01\right)$, due to different magnitudes of risk across studies. The log risk ratios of thyroid cancer linearly decreased with time since diagnosis/detection of hyperthyroidism (Balasubramaniam et al. 2012, Chen et al. 2013a, Yeh et al. 2013, Huang et al. 2017, Kitahara et al. 2018) and hypothyroidism (Balasubramaniam et al. 2012, Chen et al. 2013b, Huang et al. 2017, Kitahara et al. 2018) (Fig. 4). After 10 years of follow-up, the risk was no longer significantly increased in hypothyroid individuals (risk ratio $=0.91,95 \% \mathrm{CI} 0.26$ to $3.23, \mathrm{I}^{2}=87 \%, P<0.0001$ ), but remained elevated in hyperthyroid individuals (risk ratio $=2.50,95 \%$ CI: 1.66 to $3.78, \mathrm{I}^{2}=47 \%, P=0.02$ ). The detected outliers may indicate an under-estimation of the CI's upper bound, but the trend over time was consistent across studies.

There was a higher risk ratio for hyperthyroidism among untreated individuals (risk ratio $=6.80$, 95\%CI 3.58 to 12.91) (Yeh et al. 2013) than among those treated with RAI only (risk ratio $=1.80,95 \% \mathrm{CI}$ : 0.43 to 7.53) (Metso et al. 2007), though the difference among different treatment subgroups was not statistically significant $\left(p_{\text {heterogeneity }}=0.22\right.$, Supplementary Fig. 8). However, very few studies enabled analyses stratified https://erc.bioscientifica.com

https://doi.org/10.1530/ERC-19-0417 (c) 2020 Society for Endocrinology Published by Bioscientifica Ltd. Printed in Great Britain 

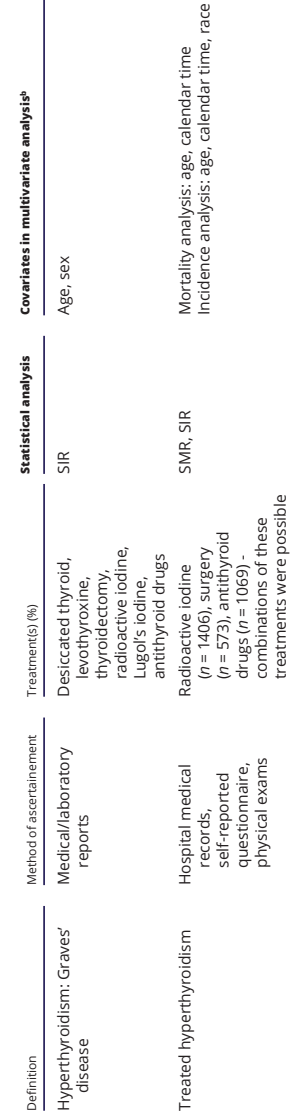

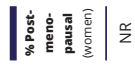

$\left|\frac{1}{3}\right|^{2}$

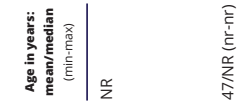

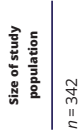

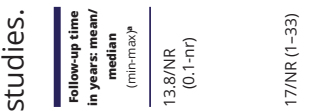

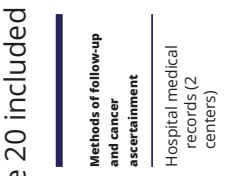
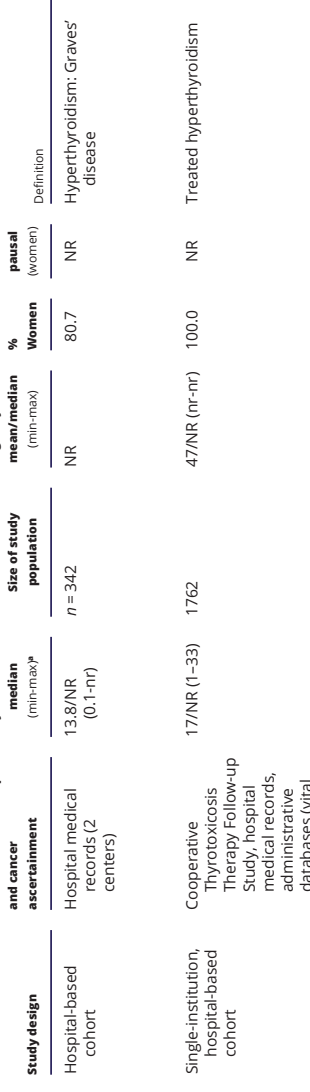

竧岁

孚

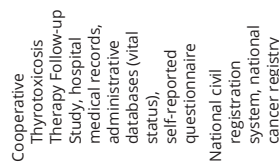

离

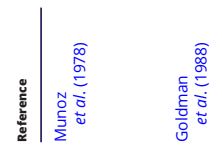

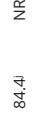
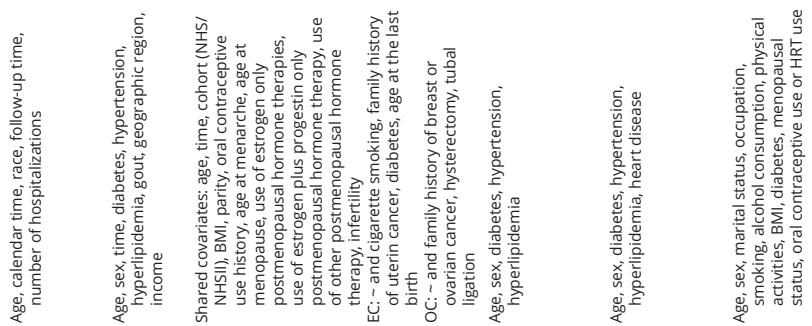

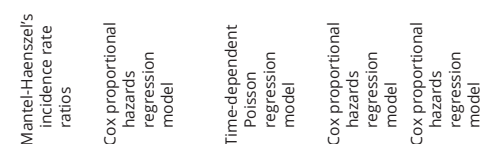
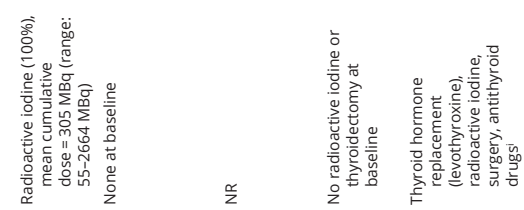

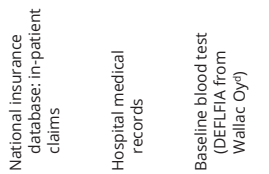
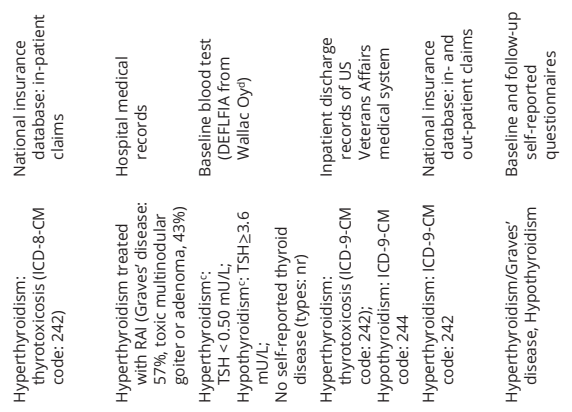

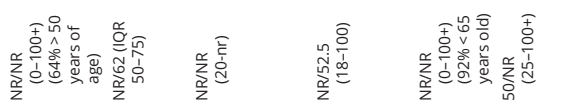
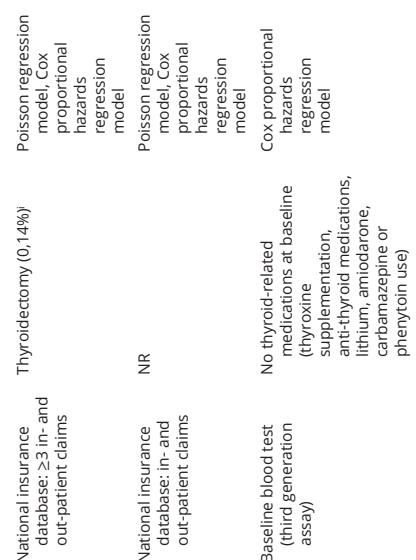

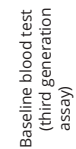
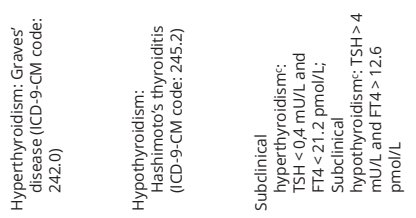

$\frac{\infty}{z}$

$\stackrel{m}{\kappa} \quad \bar{\delta} \quad$ 足

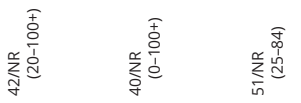

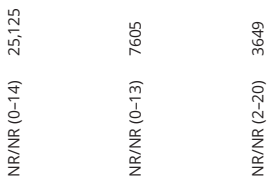

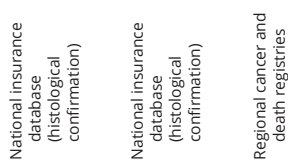

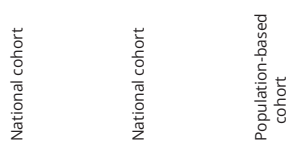

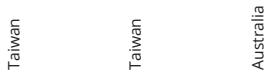

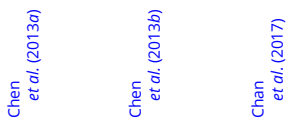




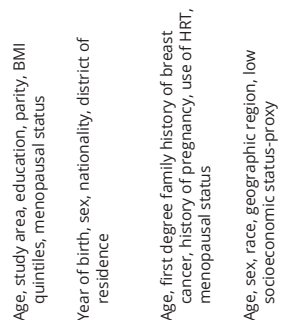

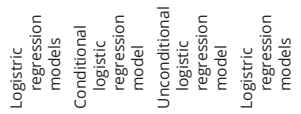

$\stackrel{\propto}{\bar{n}}$

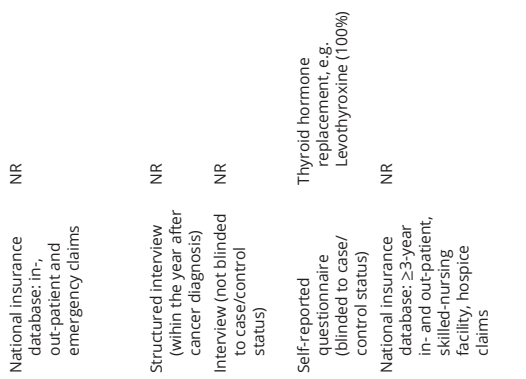

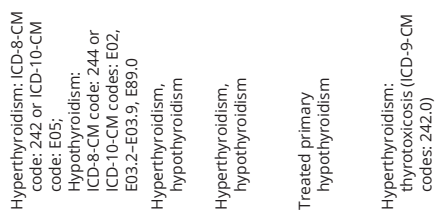

$\frac{\infty}{2}$

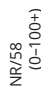

$\hat{0}$
0
$\infty$
0
0
0
11
$=$

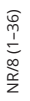

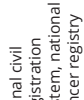

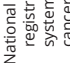

$\frac{1}{0}$
$\frac{0}{0}$
$\frac{0}{00}$
$\frac{0}{0}$
$\frac{0}{\pi}$

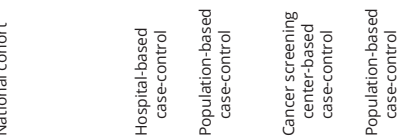

ํㅣㅁ

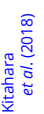
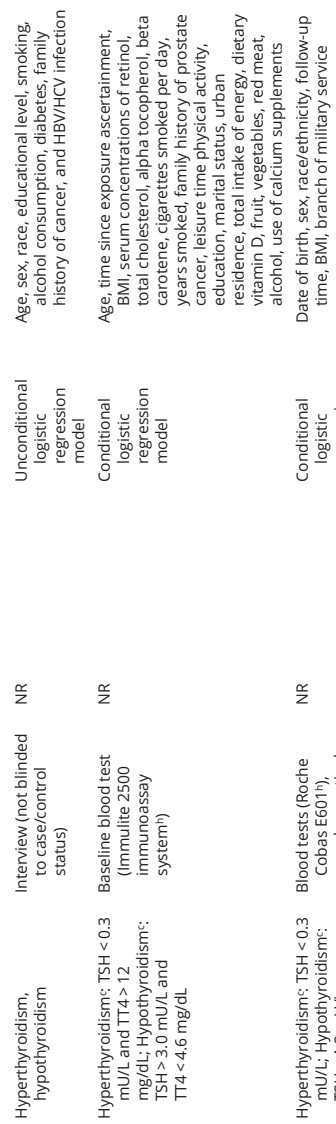

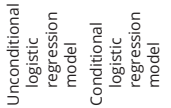
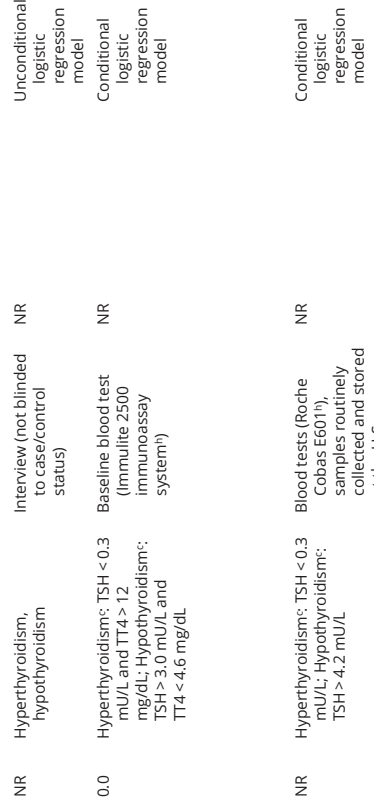

$\stackrel{\circ}{\infty}:$

㧘!

I
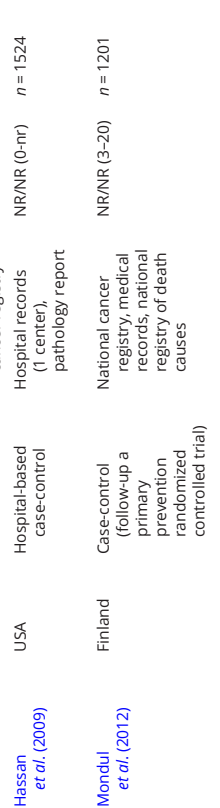
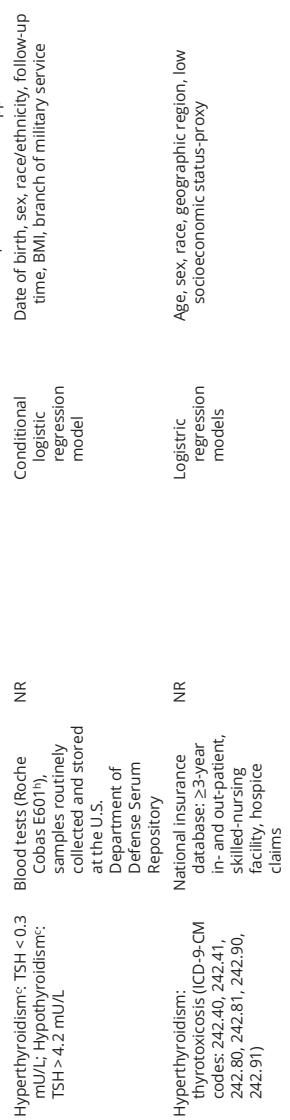

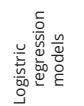

\section{$\frac{\alpha}{z}$}

家翌

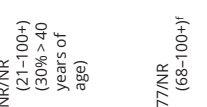

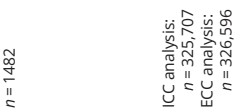

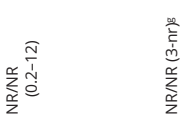

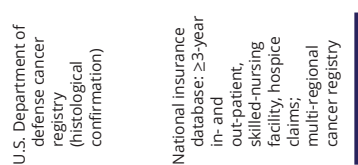

孚

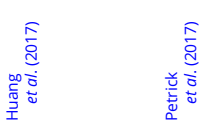

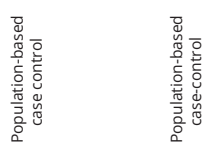

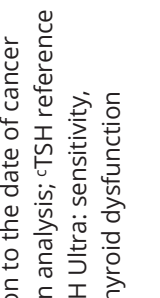

은 돈돈

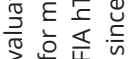

वे चै च

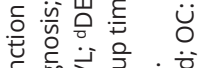

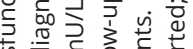

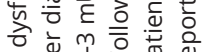

은

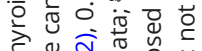

ए

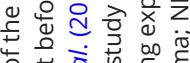

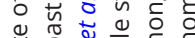

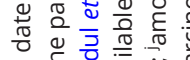

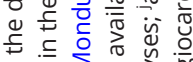

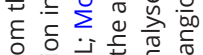

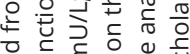

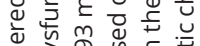

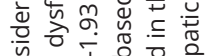

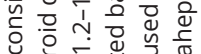

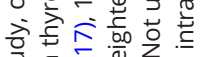

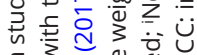

ᄃ

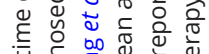

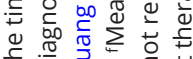

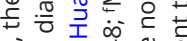

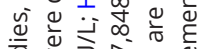

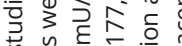

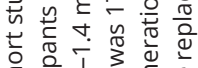

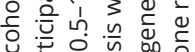

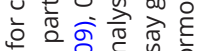

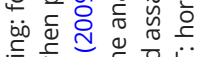

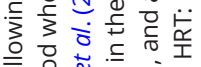

은 은

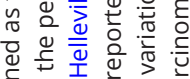

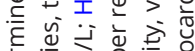

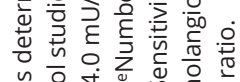

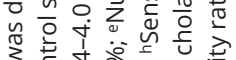

o 0 o

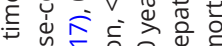

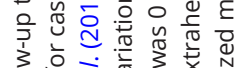

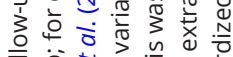

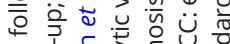

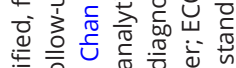

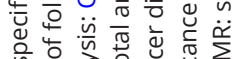

o

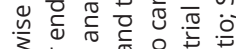

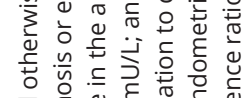




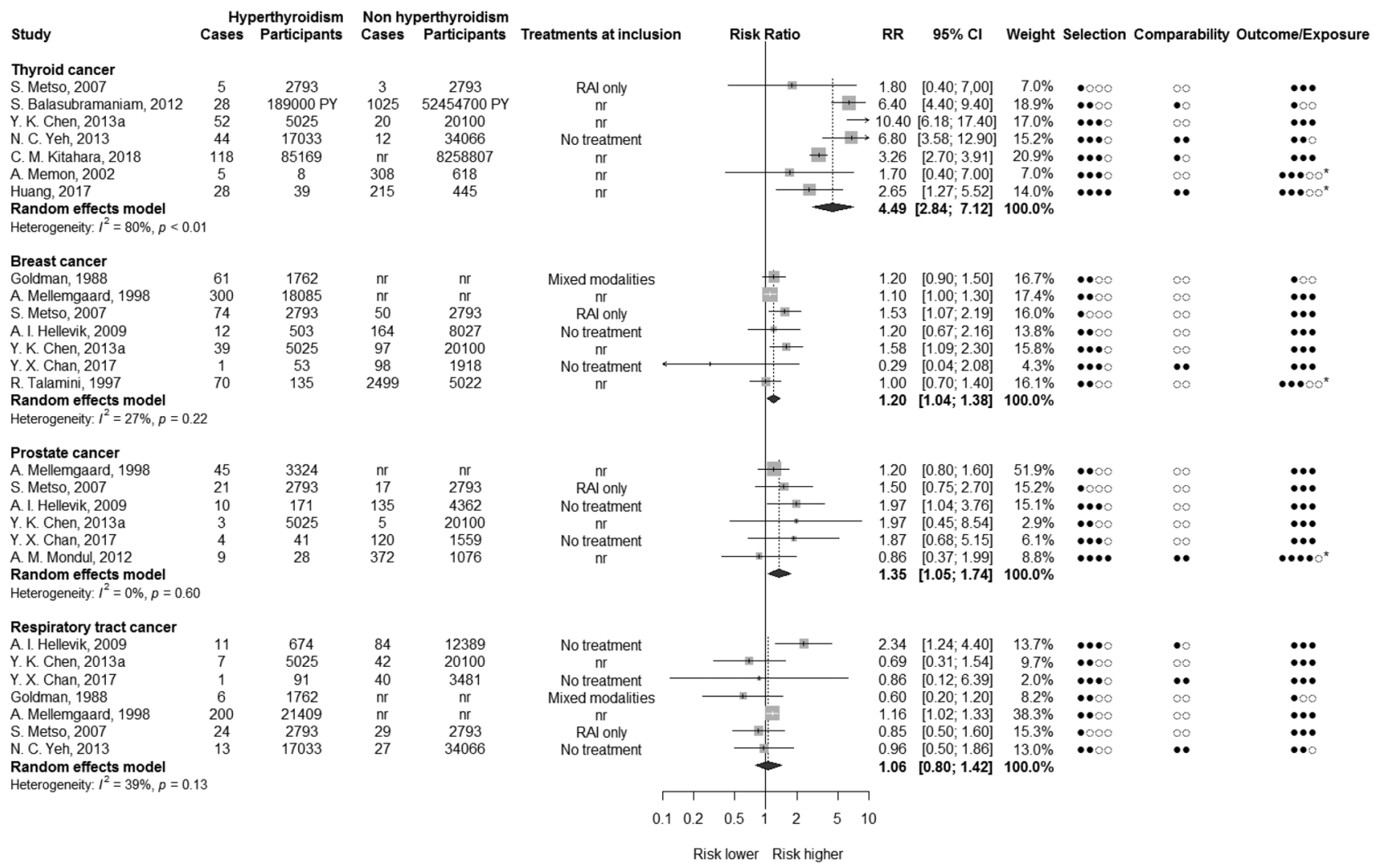

\section{Figure 2}

Forest plots for hyperthyroidism and the risk of different cancer sites and individual study risk of bias: overall risk ratios are displayed as diamonds. The size of each square is proportional to the weight of the study. Cl: confidence interval; nr: not reported; PY: person-year; RAl: radioactive iodine; RR: risk ratio. *Case-control studies. Metso et al. (2007): results estimated based on a figure reporting the primary results of the article, exact results were not available. Mellemgaard et al. (1998): results for respiratory tract cancer pooled from separate risks for men and women reported with a fixed-effect model. Yeh et al. (2013) did not adjust for smoking but did adjust for all other important factors.

by treatment modalities for hyperthyroidism and none for hypothyroidism. Men with hyperthyroidism (risk ratio $=5.12,95 \%$ CI 3.03 to 8.67 ) or hypothyroidism (risk ratio $=3.70,95 \%$ CI 1.13 to 12.17 ) had higher risks than women with the same condition (hyperthyroidism: risk ratio $=3.87$, 95\% CI: 2.44 to 6.14 ; hypothyroidism: risk ratio $=1.30$, $95 \%$ CI: 0.91 to 1.87 ), but the difference between sexes was not statistically significant

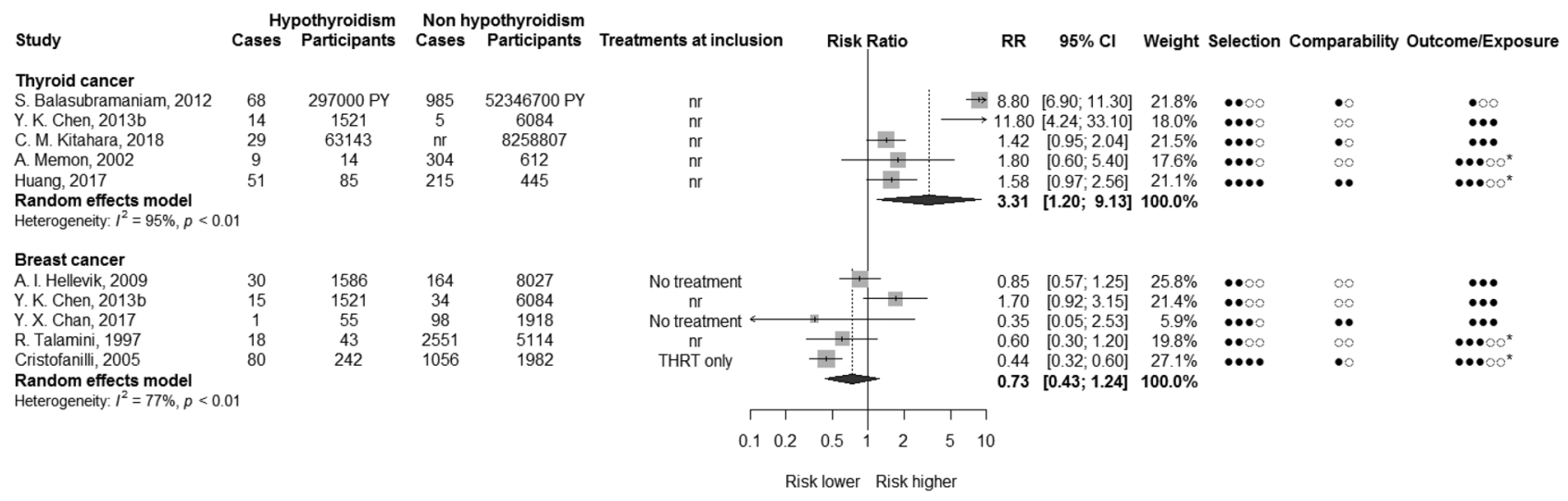

Figure 3

Forest plots for hypothyroidism and the risk of different cancer sites and individual study risk of bias: overall risk ratios are displayed as diamonds. The size of each square is proportional to the weight of the study. Cl: confidence interval; nr: not reported; PY: person-year; RR: risk ratio; THRT: thyroid hormone replacement therapy. *Case-control studies.

https://erc.bioscientifica.com

https://doi.org/10.1530/ERC-19-0417
2020 Society for Endocrinology Published by Bioscientifica Ltd. Printed in Great Britain 

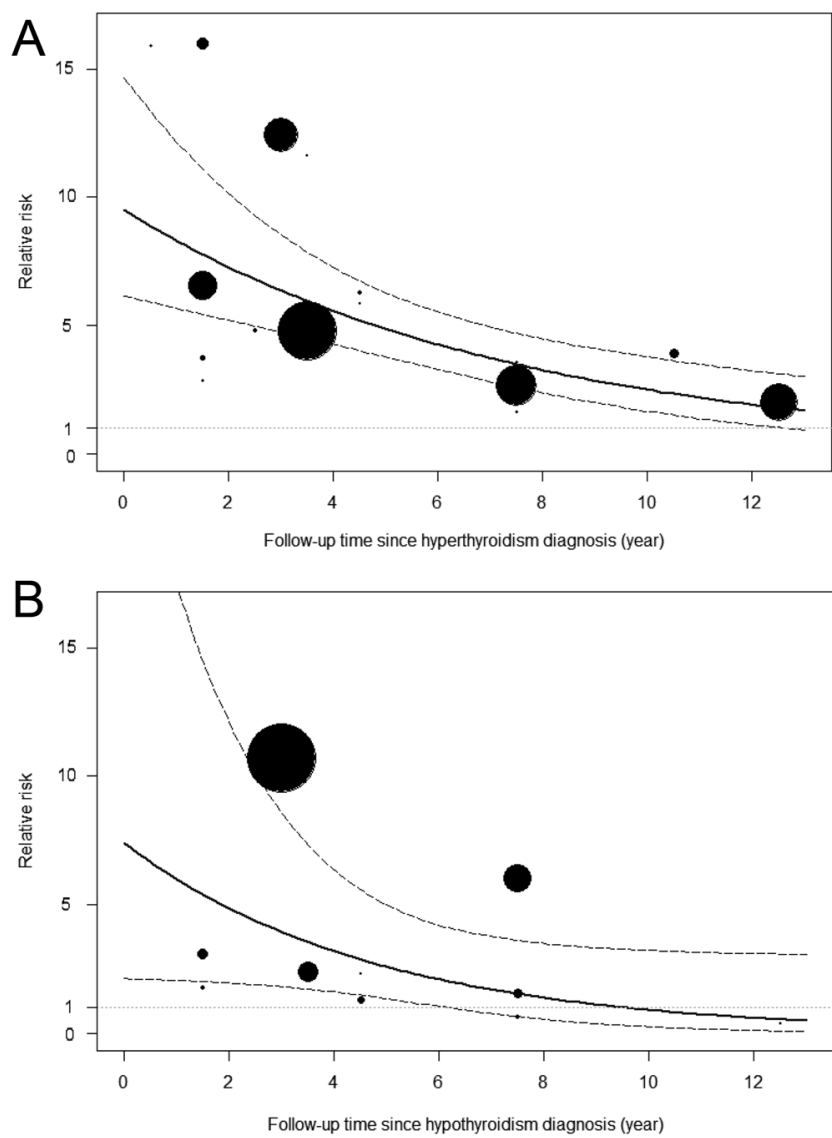

Figure 4

Effect of follow-up time on thyroid cancer risk of participants with thyroid dysfunction compared to euthyroid individuals. (A) For hyperthyroidism analysis. (B) For hypothyroidism analysis. Solid line: relative risk of thyroid cancer; dashed line: 95\% confidence interval.

$\left(\mathrm{p}_{\text {heterogeneity hyperthyroidism }}=0.43, \mathrm{p}_{\text {heterogeneity hypothyroidism }}=0.10\right)$ (Supplementary Fig. 7). Moreover, for hypothyroidism, the subgroup analysis by sex was entirely driven by one study including only men that did not allow a comparison with women (Balasubramaniam et al. 2012).

\section{Breast cancer}

Risk of breast cancer associated with hyperthyroidism or hypothyroidism was investigated in seven (Goldman et al. 1988, Talamini et al. 1997, Mellemgaard et al. 1998, Metso et al. 2007, Hellevik et al. 2009, Chen et al. 2013a, Chan et al. 2017) $(n=66,216)$ and five (Talamini et al. 1997, Cristofanilli et al. 2005, Hellevik et al. 2009, Chen et al. 2013a, Chan et al. 2017) ( $n=26,572)$ studies, respectively. Most studies had low-to-moderate risk of bias in terms of participants' selection and exposure/ outcome ascertainment. However, except in two studies (Cristofanilli et al. 2005, Chan et al. 2017), no adjustment was made for potential confounders such as hormone replacement therapy/menopausal status, parity, or family history of breast cancer. Except one study reporting only one cancer case among the exposed (Chan et al. 2017), all other studies reported statistically significant (Metso et al. 2007, Chen et al. 2013a) or non-significant (Goldman et al. 1988, Talamini et al. 1997, Mellemgaard et al. 1998, Hellevik et al. 2009) increased risks with hyperthyroidism (Fig. 2). In contrast, most studies found decreased risks with hypothyroidism, though they were based on relatively small numbers of cases and mostly reported statistically non-significant associations (Fig. 3). This decrease was statistically significant in only one large study which considered adjustment for important potential confounders such as family history of breast cancer, hormone replacement therapy, and menopausal status (Cristofanilli et al. 2005).

The pooled risk ratio was 1.20 (95\%CI: 1.04 to 1.38 , 557 cases among the exposed) for hyperthyroidism, with weak evidence of heterogeneity $\left(\mathrm{I}^{2}=27 \%, P=0.22\right)$, and 0.73 (95\%CI 0.43 to $1.24,144$ cases among the exposed) for hypothyroidism, but with a substantial degree of heterogeneity $\left(\mathrm{I}^{2}=77 \%, P<0.01\right)$. However, the only study reporting a positive association with hypothyroidism had no information on potential confounders (Chen et al. 2013b). Among the other studies, the risk estimates were relatively consistent, and the most influential study (Supplementary Fig. 18) accounted for important breast cancer risk factors (Cristofanilli et al. 2005).

The risk ratio associated with hyperthyroidism was higher among women treated with RAI only (risk ratio $=1.54$, 95\%CI 1.08 to 2.19) (Metso et al. 2007) than in untreated women (risk ratio $=0.82,95 \%$ CI 0.24 to 2.81 ) (Hellevik et al. 2009, Chan et al. 2017). Nevertheless, the difference by different treatment subgroups was not statistically significant ( $\mathrm{p}_{\text {heterogeneity }}=0.54$, Supplementary Fig. 9). In contrast, breast cancer risk significantly decreased among women treated with THRT (risk ratio=0.44, 95\%CI 0.32 to 0.60) (Cristofanilli et al. 2005), whereas no significant association with hypothyroidism was found among untreated women (risk ratio $=0.82$, 95\%CI 0.56 to 1.21) (Hellevik et al. 2009, Chan et al. 2017) ( $\mathrm{p}_{\text {heterogeneity }}$ among treatment subgroups $=0.03$, Supplementary Fig. 12).

\section{Prostate cancer}

Six (Mellemgaard et al. 1998, Metso et al. 2007, Hellevik et al. 2009, Mondul et al. 2012, Chen et al. 2013a, Chan et al. 2017) $(n=14,891)$ and four (Hellevik et al. 2009, Mondul et al. 2012, Chen et al. 2013b, Chan et al. (c) 2020 Society for Endocrinology Published by Bioscientifica Ltd. Printed in Great Britain 
2017) $(n=41,272)$ studies reported risks associated with hyperthyroidism and hypothyroidism, respectively. Risk of prostate cancer was significantly (Hellevik et al. 2009) or non-significantly (Mellemgaard et al. 1998, Metso et al. 2007, Chen et al. 2013a, Chan et al. 2017) increased with hyperthyroidism in five cohorts (Fig. 2). In contrast, except in one study reporting only one cancer case in the exposed (Chen et al. 2013b), the risk decreased with hypothyroidism in the three other studies (Hellevik et al. 2009, Mondul et al. 2012, Chan et al. 2017), one of which reached statistical significance (risk ratio $=0.48,95 \% \mathrm{CI}$ 0.28 to 0.81 ) (Supplementary Table 2).

The pooled risk ratio for hyperthyroidism was 1.35 (95\%CI 1.05 to $1.74,92$ cases among the exposed), with no evidence of heterogeneity $\left(\mathrm{I}^{2}=0 \%, P=0.60\right)$, based on studies with low risk of bias for participants' selection and exposure/outcome ascertainment. However, this risk estimate was mostly unadjusted for important potential confounders, such as family history of cancer, ethnicity, and BMI (Mellemgaard et al. 1998, Metso et al. 2007, Hellevik et al. 2009, Chen et al. 2013a, Chan et al. 2017). Furthermore, the risk ratio varied across subgroups. In particular, it was higher in untreated men (risk ratio $=1.94$, 95\%CI 1.13 to 3.34) (Hellevik et al. 2009, Chan et al. 2017) than in those treated by RAI (risk ratio $=1.50,95 \% \mathrm{CI} 0.79$ to 2.85) (Metso et al. 2007), even though the difference among different treatment subgroups was not significant $\left(p_{\text {heterogeneity }}=0.27\right.$, Supplementary Table 10$)$. Given the limited number of studies, we combined the published risk estimates for hypothyroidism with a random-effect model, for exploratory purposes, and found a pooled risk ratio of 0.70 (95\%CI 0.45 to $1.07,46$ cases among the exposed) with a low level of heterogeneity $\left(\mathrm{I}^{2}=23 \%, P=0.3\right)$.

\section{Respiratory tract cancer}

A total of 121,616 individuals were included in seven cohorts on hyperthyroidism (Goldman et al. 1988, Mellemgaard et al. 1998, Metso et al. 2007, Hellevik et al. 2009, Chen et al. 2013a, Yeh et al. 2013, Chan et al. 2017). Two studies indicated a significantly increased risk (Mellemgaard et al. 1998, Hellevik et al. 2009), while the five others did not show any association based on the few cases (Fig. 2). The pooled risk ratio was 1.06 (95\% CI 0.80 to $1.42,262$ cases among the exposed), with weak evidence of heterogeneity $\left(I^{2}=39 \%, P=0.13\right)$. Heterogeneity was possibly explained by a study reporting a 2 -fold higher risk among hyperthyroid individuals (Hellevik et al. 2009), while the others found no association or a marginally increased risk (Supplementary Fig. 16). All but two (Goldman et al.
1988, Metso et al. 2007) studies had moderate-to-low risk of bias in terms of participants' selection and outcome ascertainment, but most studies lacked data on potential confounding factors such as smoking history and family history of cancer (Goldman et al. 1988, Mellemgaard et al . 1998, Metso et al. 2007, Chen et al. 2013a, Yeh et al. 2013). The pooled risk ratio restricted to the two studies providing estimates adjusted for important confounding factors, including smoking, was 2.13 (95\%CI 1.17 to 3.90, 12 cases among the exposed) (Hellevik et al. 2009, Chan et al. 2017) (Supplementary Table 6). The results did not statistically differ between the three studies reporting risks restricted to lung cancer and the four studies investigating all respiratory tract cancers combined $(P=0.81$, Supplementary Table 6). However, they varied according to hyperthyroidism treatment modalities, with a pooled risk ratio of $1.42(95 \% \mathrm{CI}$ 0.70 to 2.88 ) among untreated individuals (Hellevik et al. 2009, Yeh et al. 2013, Chan et al. 2017) and 0.85 (95\% CI 0.48 to 1.52) among individuals treated with RAI (Metso et al. 2007), but the difference by different treatment subgroups was not significant ( $p_{\text {heterogeneity }}=0.47$, Supplementary Fig. 11). Of three studies investigating the association between hypothyroidism and respiratory tract cancer risk, one study reported a non-significantly decreased risk of 0.87 (95\%CI 0.43 to 1.74) (Hellevik et al. 2009) and two others reported no cancer case in the exposed group (Chen et al. 2013, Chan et al. 2017).

\section{Other outcomes}

Risk estimates from individual studies on other cancer sites are reported in Supplementary Tables 1 and 2. Two large case-control studies reported significantly increased risks of extra- and/or intra-hepatic cholangiocarcinoma with hyperthyroidism, based on a total of 162 cases among the exposed (Welzel et al. 2007, Petrick et al. 2017). Two other studies reported non-significantly elevated liver cancer risks in hyperthyroid individuals, based on only 13 and 8 cases respectively (Hassan et al. 2009, Chen et al. 2013a). The estimated liver cancer risks with hypothyroidism were inconsistent across studies (Hassan et al. 2009, Chen et al. 2013b). We also identified three studies investigating brain cancer risk, which suggested an increased risk (varying from 1.3 to 2.3 ) with hyperthyroidism (Goldman et al. 1988, Mellemgaard et al . 1998, Metso et al. 2007) based on a few cases. No study provided results on the hypothyroidism-brain cancer risk association. Renal cancer risk also appeared elevated among hyperthyroid individuals (Mellemgaard et al. 1998, Metso et al. 2007, Chen et al. 2013a), with significantly 
increased risks in two studies (risk ratio $=2.32,95 \% \mathrm{CI}$ : 1.06 to 5.01, 20 cases among the exposed (Metso et al. 2007 ); risk ratio $=1.3,95 \% \mathrm{CI}: 1.0$ to $1.8,44$ cases among the exposed (Mellemgaard et al. 1998)). Last, two studies reported a non-significantly decreased risk ratio (varying from 0.8 to 0.9 ) of skin cancer associated with hyperthyroidism (Mellemgaard et al. 1998, Metso et al. 2007). Very little data were available for other outcomes.

\section{Other sensitivity and subgroup analyses}

No substantial difference in the estimated risk ratios was observed between random- and fixed-effect models (Supplementary Tables 3, 4, 5 and 6). For all outcomes and exposure groups, cohorts yielded higher risk ratios than case-control studies. The pooled risk ratios for breast and thyroid cancers were also higher in studies where thyroid dysfunction was assessed through hospital or health insurance databases compared to studies using blood measurements or self-reported data. Subsequently, studies conducted in Europe reported the smallest risk estimates for all outcomes, while those conducted in Asia yielded the highest risk estimates. However, pooled risk ratios did not statistically differ among regions, with the exception of breast cancer after hypothyroidism. Other sensitivity-, subgroup-, and influence analyses did not substantially modify the results (Supplementary Figs 13, 14, 15, 17 and Supplementary Tables 3, 4, 5, 6).

\section{Discussion}

This systematic review uncovered several studies evaluating the relationship between thyroid dysfunction, mostly as overt disorder, and cancer risk by tumor site, including thyroid, breast, prostate, respiratory tract, liver, brain, kidney, and skin cancers. Our meta-analysis of 15 cohort and case-control studies showed that hyperthyroidism was associated with 20\%, 35\%, and 4.5-fold higher risks of breast, prostate, and thyroid cancer, respectively, compared to euthyroidism. We found no clear evidence of an association between hyperthyroidism and other site-specific cancer risks, based on very few studies. Hypothyroidism was significantly associated with a 3-fold higher risk of thyroid cancer, which was limited to the first 10 years after diagnosis of hypothyroidism. Hypothyroidism was not significantly associated with risk of other cancer sites, including breast and prostate cancers.

While previous reviews focused on thyroid and breast cancers (Sarlis et al. 2002, Angelousi et al. 2012, Hardefeldt et al. 2012, Fang et al. 2017), the present review is the first one to report associations between hyperthyroidism and hypothyroidism and risk of a wide range of cancer types and pooled risk estimates for prostate and respiratory tract cancers. Our findings are partly consistent with previous meta-analyses. A previous metaanalysis of 12 case-control studies published through 1997 reported an increased thyroid cancer risk associated with self-reported hyperthyroidism (diagnosed at least one year prior to cancer diagnosis) in both women (risk ratio $=1.4$, 95\%CI: 1.0 to 2.1 ) and men (risk ratio $=3.1,95 \% \mathrm{CI}: 1.0$ to 9.8), but not with hypothyroidism (Franceschi et al. 1999). This study found weaker associations for both types of thyroid dysfunction compared to ours. This might be explained by differing practices in the management of hyperthyroidism according to age and country. Treatment of hyperthyroidism, especially when using radioactive iodine, often results in hypothyroidism. This may thus lead to somewhat confounded risk associations with hypothyroidism in the most recent studies, due to a higher proportion of hypothyroid individuals who were previously treated for hyperthyroidism than in the past studies. Moreover, most recent studies may benefit from a better thyroid dysfunction diagnosis and/or enhanced cancer surveillance strategies in the most recent years. Indeed, there is now evidence that increased TSH levels is a marker of thyroid cancer among patients with nodules, with a dose-response relationship (McLeod et al. 2012, $\mathrm{Hu}$ et al. 2016). Our results are compatible with recent findings of an inverse association between prediagnosis TSH levels and thyroid cancer risk in a healthy population (Rinaldi et al. 2014) and common genetic variants for low TSH levels and thyroid cancer (Gudmundsson et al. 2012).

Unlike previous meta-analyses (Hardefeldt et al. 2012, Fang et al. 2017), we found a significantly increased risk of breast cancer with hyperthyroidism after inclusion of a recent, large longitudinal study (Chen et al. 2013a) and exclusion of studies with prevalent cancers where thyroid dysfunction might result from cancer symptoms or treatment toxicities. Our findings are compatible with two recent large cohort studies reporting an elevated breast cancer risk in relation to increasing T4 and T3 levels within normal ranges (Tosovic et al. 2010, 2012). They are also consistent with previous meta-analyses which reported no association between hypothyroidism and breast cancer risk (Angelousi et al. 2012).

High heterogeneity across individual studies was observed for thyroid and breast cancers, but not for other cancer sites. Risk estimates widely varied across studies in terms of magnitude of thyroid cancer risk with hyperthyroidism (risk ratios ranging from 1.7 to 10.4) 
or hypothyroidism (risk ratios ranging from 1.8 to 11.8), and in terms of direction of the association between hypothyroidism and breast cancer. The different ascertainment methods of thyroid dysfunction across studies is probably one factor explaining this heterogeneity, since higher risks were estimated in studies based on hospital or health insurance data compared to populationbased studies using blood measurements or self-reported data. The different risk estimates between hospital- and population-based studies may also reflect different severity degrees of thyroid dysfunction or comorbidities - but data were lacking to investigate this hypothesis. Differences in potential confounding factors, for example, calendar year, family cancer history, or menopausal status, can also account for some heterogeneity, but these data were lacking in many studies (Talamini et al. 1997, Memon et al. 2002, Metso et al. 2007, Hellevik et al. 2009, Chen et al. 2013a,b), particularly in those based on health insurance databases.

Biological mechanisms underlying associations between thyroid dysfunction and cancer are not well known, but a number of hypotheses have been suggested in in vitro and in vivo studies. TSH has been found to stimulate follicular thyroid cell growth and differentiation (Hard 1998). T3 and T4 can be anti-apoptotic and have a proliferative effect on thyroid, breast, and prostate cancer cell lines by regulating gene expression (TGF- $\alpha$, B-cell translocation gene 2) (Tsui et al. 2008, Pinto et al. 2011), causing phosphorylation by MAPK pathways, binding in the integrin $\alpha v \beta 3$ (Moeller \& Führer 2013, Hercbergs et al. 2018), and stimulating estrogen-like effects (Dinda et al. 2002). Moreover, excessive or insufficient iodine intake, which plays a key role in thyroid hormone production, could also be a risk factor of breast and thyroid cancers (Dong et al. 2018). Current experimental evidence thus support epidemiological findings on a positive association between hyperthyroidism and cancer risk.

Nonetheless, the interpretation of those findings as a causal relationship between hyperthyroidism and cancer incidence is not straightforward. Indeed, thyroid dysfunction can be subsequent to cancer or cancer treatments. Our study minimized the possibility of reverse causation by excluding prevalent or previous cancer cases at the time of thyroid dysfunction diagnosis/detection. However, the decreased pooled risk ratios of thyroid cancer with time since thyroid dysfunction diagnosis/ detection (Fig. 4) are suggestive of a surveillance bias (e.g. incidental cancer cases detected by thyroidectomy for hyperthyroidism treatment) in the first years of follow-up. Nevertheless, while thyroid cancer risk was no longer increased in hypothyroid individuals after 10 years of follow-up, it remained significantly increased in hyperthyroid individuals with a risk ratio of 2.50 (95\%CI: 1.66 to 3.78 ) compared to euthyroid individuals. Unfortunately, few studies have reported data on tumor histology (Huang et al. 2017, Kitahara et al. 2018), size (Cristofanilli et al. 2005, Huang et al. 2017) and stage at diagnosis (Cristofanilli et al. 2005, Kitahara et al. 2018), which could strengthen the assessment of a potential surveillance bias. Though risk factors (e.g. iodine intake, radiation exposure) and age at diagnosis differ according to thyroid cancer histology (Aschebrook-Kilfoy et al. 2013, Liu et al. 2017), Kitahara et al. (2018) found very similar thyroid dysfunction-related risks for papillary and follicular thyroid cancers. The authors nevertheless reported a higher hyperthyroidism-related risk for localized thyroid cancer than regional/distant thyroid cancer as compared to the general population, which suggests that a certain proportion of, but not all, the increased risk related to hyperthyroidism may be due to a surveillance bias. This study also showed a non-significantly increased risk of localized thyroid cancer with hypothyroidism, but no association for regional/distant cancer (based on very few cancer cases), which is also indicative of a surveillance bias. Similarly, Cristofanilli et al. (2005) found that, among women diagnosed with breast cancer, hypothyroid women were more frequently diagnosed with an earlystage or small-size $(\leq 2 \mathrm{~cm})$ tumor than euthyroid women. Current evidence thus suggest that part of the thyroid dysfunction-related excess risks may be associated with non-clinically relevant thyroid and breast cancers, but this should be confirmed (Staniforth et al. 2016, Lim et al. 2017). The remaining elevated risk, 10 years after thyroid dysfunction diagnosis/detection, may also reflect the effect of underlying autoimmune diseases, which are associated with increased risk of thyroid and breast cancer (Shu et al. 2010, Resende de Paiva et al. 2017).

The estimated cancer risks could have also been mediated or modified by thyroid dysfunction treatments. Indeed, our results show differences in risk estimates by treatment modalities (Supplementary Figs 8, 9, 10, 11 and 12), for example, hypothyroid women treated with THRT had a reduced risk of breast cancer, whereas no significant association was found among untreated hypothyroid women. However, very few studies contributed to the analyses stratified by treatments, and treatmentspecific risk estimates were available only for RAI and THRT, which was insufficient for the interpretation of the role of thyroid dysfunction treatments in the relationship between thyroid dysfunction and cancer risk. 
Moreover, as the populations may differ in many other aspects than treatments, it remains very difficult to disentangle whether those differences reflect the impact of the treatment itself, its impact on thyroid dysfunction, or different severities of thyroid dysfunction and associated comorbidities.

The present study has several strengths. We conducted an extensive and systematic literature search on the association between both hyper- and hypothyroidism and cancer risk, with no restriction to cancer type. This enabled us to report results on cancer sites that have not been considered in previous meta-analyses (e.g. prostate and respiratory tract cancer) and investigate the possible role of thyroid hormones for hormone-dependent (e.g. thyroid, breast, and prostate cancers) and non-hormonedependent cancers (e.g. respiratory tract cancer). Unlike previous meta-analyses, we applied no restriction on the method for thyroid dysfunction ascertainment to retrieve a maximal number of relevant publications. However, we excluded studies with cancer history prior to thyroid dysfunction diagnosis/detection to minimize the possibility of reverse causation. Subgroup and sensitivity analyses were conducted to explore potential factors that could explain heterogeneity of results

There are also several limitations to our study. Firstly, data on treatments and important potential confounding factors (e.g. family history of cancer, BMI, and reproductive factors) were lacking in most studies, which prevented us from investigating their impact on the risk estimates. In addition, even though information was available on time since thyroid dysfunction diagnosis/detection, no data were available on the duration of overt dysfunctional state and status after thyroid dysfunction treatment (e.g. euthyroidism or hypothyroidism after treatment for hyperthyroidism). Secondly, high levels of heterogeneity were found for thyroid cancer after hypo- or hyperthyroidism and breast cancer after hypothyroidism. Outliers were also observed in the analysis of follow-up time. This questions the robustness of the pooled risk estimates. Last, different measures of association (relative risk, odds ratio, hazard ratio, and standardized incidence ratio) were pooled together, which involves the following assumptions: rare outcome (for odds ratio and hazard ratio), no association between the exposure and censoring status (for hazard ratio), and the use of data from the general population as a comparison group (for standardized incidence ratio) (Goldman et al. 1988, Mellemgaard et al. 1998, Kitahara et al. 2018), which were nevertheless verified for most studies.

In conclusion, current evidence from epidemiological studies showed that hyperthyroidism is associated with increased risks of thyroid, breast, and prostate cancers, compared to euthyroidism. Hypothyroidism is associated with an increased risk of thyroid cancer within the first 10 years of follow-up. However, it remains unclear whether these findings represent causal relationships because information on important potential confounders, thyroid dysfunction treatments, associated comorbidities, underlying disease, cancer stage at diagnosis, and histology was lacking in most studies. Further prospective studies should investigate possible confounding or mediating effects of treatments, comorbidities, and major cancer risk factors on the associations between thyroid dysfunction and cancer risk.

\section{Supplementary materials}

This is linked to the online version of the paper at https://doi.org/10.1530/ ERC-19-0417.

\section{Declaration of interest}

The authors declare that there is no conflict of interest that could be perceived as prejudicing the impartiality of the research reported.

\section{Funding}

Thi-Van-Trinh Tran received a doctoral grant from the Paris Sud-Paris Saclay University.

\section{Ethics approval and consent to participate}

This systematic review and meta-analysis only used published data, with no access to individual data. No ethical approval or participants' consent to participate was thus required for this study.

\section{Data availability}

All data reported in this manuscript can be found in the original articles mentioned in the list of references.

\section{Author contribution statement}

$\mathrm{T} T \mathrm{~V} T$ and $\mathrm{N}$ J designed the study protocol, performed the literature search, extracted data from the original articles and assessed risk of biases of the included studies, and drafted the first version of the manuscript. T TVT conducted the statistical analyses. CM K, FD, and M C B R contributed to the interpretation of the results and the drafting of the paper. All coauthors approved the publication of the manuscript in its final version.

\section{References}

Angelousi AG, Anagnostou VK, Stamatakos MK, Georgiopoulos GA \& Kontzoglou KC 2012 MECHANISMS IN ENDOCRINOLOGY: Primary HT and risk for breast cancer: a systematic review and meta-analysis. European Journal of Endocrinology 166 373-381. (https://doi. org/10.1530/EJE-11-0838) (c) 2020 Society for Endocrinology Published by Bioscientifica Ltd. Printed in Great Britain 
Aschebrook-Kilfoy B, Grogan RH, Ward MH, Kaplan E \& Devesa SS 2013 Follicular thyroid cancer incidence patterns in the United States, 1980-2009. Thyroid 23 1015-1021. (https://doi.org/10.1089/ thy.2012.0356)

Balasubramaniam S, Ron E, Gridley G, Schneider AB \& Brenner AV 2012 Association between benign thyroid and endocrine disorders and subsequent risk of thyroid cancer among 4.5 million US male veterans. Journal of Clinical Endocrinology and Metabolism 97 2661-2669. (https://doi.org/10.1210/jc.2011-2996)

Brandt F, Thvilum M, Almind D, Christensen K, Green A, Hegedüs L \& Brix TH 2013 Morbidity before and after the diagnosis of hyperthyroidism: a nationwide register-based study. PLOS ONE $\mathbf{8}$ e66711. (https://doi.org/10.1371/journal.pone.0066711)

Chan YX, Knuiman MW, Divitini ML, Brown SJ, Walsh J \& Yeap BB 2017 Lower TSH and higher free thyroxine predict incidence of prostate but not breast, colorectal or lung cancer. European Journal of Endocrinology 177 297-308. (https://doi.org/10.1530/EJE-17-0197)

Chen YK, Lin CL, Chang YJ, Cheng FT-F, Peng CL, Sung FC, Cheng YH \& Kao CH 2013a Cancer risk in patients with Graves' disease: a nationwide cohort study. Thyroid 23 879-884. (https://doi. org/10.1089/thy.2012.0568)

Chen YK, Lin CL, Cheng FT, Sung FC \& Kao CH 2013b Cancer risk in patients with Hashimoto's thyroiditis: a nationwide cohort study. British Journal of Cancer 109 2496-2501. (https://doi.org/10.1038/ bjc.2013.597)

Cristofanilli M, Yamamura Y, Kau SW, Bevers T, Strom S, Patangan M, Hsu L, Krishnamurthy S, Theriault RL \& Hortobagyi GN 2005 Thyroid hormone and breast carcinoma: primary hypothyroidism is associated with a reduced incidence of primary breast carcinoma. Cancer 103 1122-1128. (https://doi.org/10.1002/cncr.20881)

DerSimonian R \& Laird N 1986 Meta-analysis in clinical trials. Controlled Clinical Trials 7 177-188. (https://doi.org/10.1016/01972456(86)90046-2)

Dinda S, Sanchez A \& Moudgil V 2002 Estrogen-like effects of thyroid hormone on the regulation of tumor suppressor proteins, p53 and retinoblastoma, in breast cancer cells. Oncogene 21 761-768. (https:// doi.org/10.1038/sj.onc.1205136)

Dong L, Lu J, Zhao B, Wang W \& Zhao Y 2018 Review of the possible association between thyroid and breast carcinoma. World Journal of Surgical Oncology 16 130. (https://doi.org/10.1186/s12957-018-1436-0)

Egger M, Smith GD, Schneider M \& Minder C 1997 Bias in metaanalysis detected by a simple, graphical test. BMJ 315 629-634. (https://doi.org/10.1136/bmj.315.7109.629)

Fang Y, Yao L, Sun J, Yang R, Chen Y, Tian J, Yang K \& Tian L 2017 Does thyroid dysfunction increase the risk of breast cancer? A systematic review and meta-analysis. Journal of Endocrinological Investigation 40 1035-1047. (https://doi.org/10.1007/s40618-017-0679-x)

Forman D, Bray F, Brewster D, Gombe Mbalawa C, Kohler B, Piñeros M, Steliarova-Foucher E, Swaminathan R \& Ferlay J 2013 Cancer incidence in five continents, Vol. X. Lyon, France: IARC. (available at: http://ci5.iarc.fr/CI5-X/Default.aspx)

Franceschi S, Preston-Martin S, Dal Maso L, Negri E, La Vecchia C, Mack WJ, McTiernan A, Kolonel L, Mark SD, Mabuchi K, et al. 1999 A pooled analysis of case-control studies of thyroid cancer. IV. Benign thyroid diseases. Cancer Causes and Control 10 583-595. (https://doi.org/10.1023/a:1008907227706)

Garmendia Madariaga A, Santos Palacios S, Guillén-Grima F \& Galofré JC 2014 The incidence and prevalence of thyroid dysfunction in Europe: a meta-analysis. Journal of Clinical Endocrinology and Metabolism 99 923-931. (https://doi.org/10.1210/ jc.2013-2409)

Goldman MB, Maloof F, Monson RR, Aschengrau A, Cooper DS \& Ridgway EC 1988 Radioactive iodine therapy and breast cancer: a follow-up study of hyperthyroid women. American Journal of Epidemiology 127 969-980. (https://doi.org/10.1093/oxfordjournals. aje.a114900)
Gudmundsson J, Sulem P, Gudbjartsson DF, Jonasson JG, Masson G, He H, Jonasdottir A, Sigurdsson A, Stacey SN, Johannsdottir H, et al. 2012 Discovery of common variants associated with low TSH levels and thyroid cancer risk. Nature Genetics 44 319-322. (https://doi. org/10.1038/ng.1046)

Hard GC 1998 Recent developments in the investigation of thyroid regulation and thyroid carcinogenesis. Environmental Health Perspectives 106 427-436. (https://doi.org/10.1289/ehp.1061533202)

Hardefeldt PJ, Eslick GD \& Edirimanne S 2012 Benign thyroid disease is associated with breast cancer: a meta-analysis. Breast Cancer Research and Treatment 133 1169-1177. (https://doi.org/10.1007/s10549-0122019-3)

Hassan MM, Kaseb A, Li D, Patt YZ, Vauthey JN, Thomas MB, Curley SA, Spitz MR, Sherman SI, Abdalla EK, et al. 2009 Association between hypothyroidism and hepatocellular carcinoma: a case-control study in the United States. Hepatology 49 1563-1570. (https://doi. $\operatorname{org} / 10.1002 /$ hep.22793)

Hellevik AI, Åsvold BO, Bjøro T, Romundstad PR, Nilsen TIL \& Vatten LJ 2009 Thyroid function and cancer risk: a prospective population study. Cancer Epidemiology, Biomarkers and Prevention 18 570-574. (https://doi.org/10.1158/1055-9965.EPI-08-0911)

Hercbergs A, Mousa SA, Leinung M, Lin HY \& Davis PJ 2018 Thyroid hormone in the clinic and breast cancer. Hormones and Cancer 9 139-143. (https://doi.org/10.1007/s12672-018-0326-9)

Higgins JP \& Thompson SG 2002 Quantifying heterogeneity in a meta-analysis. Statistics in Medicine 21 1539-1558. (https://doi. org/10.1002/sim.1186)

Hu N, Li ZM, Liu JF, Zhang ZZ \& Wang LS 2016 An overall and doseresponse meta-analysis for thyrotropin and thyroid cancer risk by histological type. Oncotarget 7 47750-47759. (https://doi. org/10.18632/oncotarget.10282)

Huang H, Rusiecki J, Zhao N, Chen Y, Ma S, Yu H, Ward MH, Udelsman R \& Zhang Y 2017 Thyroid-stimulating hormone, thyroid hormones, and risk of papillary thyroid cancer: a nested case-control study. Cancer Epidemiology, Biomarkers and Prevention 26 1209-1218. (https://doi.org/10.1158/1055-9965.EPI-16-0845)

Journy NMY, Bernier MO, Doody MM, Alexander BH, Linet MS \& Kitahara CM 2017 Hyperthyroidism, hypothyroidism, and causespecific mortality in a large cohort of women. Thyroid $\mathbf{2 7}$ 1001-1010. (https://doi.org/10.1089/thy.2017.0063)

Kang JH, Kueck AS, Stevens R, Curhan G, De Vivo I, Rosner B, Alexander E \& Tworoger SS 2013 A large cohort study of hypothyroidism and hyperthyroidism in relation to gynecologic cancers. Obstetrics and Gynecology International 2013743721. (https://doi.org/10.1155/2013/743721)

Kitahara CM, Körmendiné Farkas D, Jørgensen JOL, Cronin-Fenton D \& Sørensen HT 2018 Benign thyroid diseases and risk of thyroid cancer: a nationwide cohort study. Journal of Clinical Endocrinology and Metabolism 103 2216-2224. (https://doi.org/10.1210/jc.201702599)

Laurberg P, Knudsen N, Andersen S, Carlé A, Pedersen IB \& Karmisholt J 2012 Thyroid function and obesity. European Thyroid Journal 1 159-167. (https://doi.org/10.1159/000342994)

Lim H, Devesa SS, Sosa JA, Check D \& Kitahara CM 2017 Trends in thyroid cancer incidence and mortality in the United States, 19742013. JAMA 317 1338-1348. (https://doi.org/10.1001/ jama.2017.2719)

Liu Y, Su L \& Xiao H 2017 Review of factors related to the thyroid cancer epidemic. International Journal of Endocrinology 20175308635. (https://doi.org/10.1155/2017/5308635)

McLeod DS, Watters KF, Carpenter AD, Ladenson PW, Cooper DS \& Ding EL 2012 Thyrotropin and thyroid cancer diagnosis: a systematic review and dose-response meta-analysis. Journal of Clinical Endocrinology and Metabolism 97 2682-2692. (https://doi. org/10.1210/jc.2012-1083) 
Mellemgaard A, From G, Jørgensen T, Johansen C, Olsen JH \& Perrild H 1998 Cancer risk in individuals with benign thyroid disorders. Thyroid 8 751-754. (https://doi.org/10.1089/thy.1998.8.751)

Memon A, Varghese A \& Suresh A 2002 Benign thyroid disease and dietary factors in thyroid cancer: a case-control study in Kuwait. British Journal of Cancer 86 1745-1750. (https://doi.org/10.1038/sj. bjc.6600303)

Metso S, Auvinen A, Huhtala H, Salmi J, Oksala H \& Jaatinen P 2007 Increased cancer incidence after radioiodine treatment for hyperthyroidism. Cancer 109 1972-1979. (https://doi.org/10.1002/ cncr.22635)

Minlikeeva AN, Freudenheim JL, Cannioto RA, Eng KH, Szender JB, Mayor P, Etter JL, Cramer DW, Diergaarde B, Doherty JA, et al. 2017 History of thyroid disease and survival of ovarian cancer patients: results from the Ovarian Cancer Association Consortium, a brief report. British Journal of Cancer 117 1063-1069. (https://doi. org/10.1038/bjc.2017.267)

Moeller LC \& Führer D 2013 Thyroid hormone, thyroid hormone receptors, and cancer: a clinical perspective. Endocrine-Related Cancer 20 R19-R29. (https://doi.org/10.1530/ERC-12-0219)

Moher D, Liberati A, Tetzlaff J, Altman DG \& PRISMA Group 2009 Preferred reporting items for systematic reviews and meta-analyses: the PRISMA statement. Annals of Internal Medicine 151 264-249. (https://doi.org/10.7326/0003-4819-151-4-200908180-00135)

Mondul AM, Weinstein SJ, Bosworth T, Remaley AT, Virtamo J \& Albanes D 2012 Circulating thyroxine, thyroid-stimulating hormone, and hypothyroid status and the risk of prostate cancer. PLOS ONE $\mathbf{7}$ e47730. (https://doi.org/10.1371/journal.pone.0047730)

Munoz JM, Gorman CA, Elveback LR \& Wentz JR 1978 Incidence of malignant neoplasms of all types in patients with Graves' disease. Archives of Internal Medicine 138 944-947. (https://doi.org/10.1001/ archinte.1978.03630310034015)

Petitti DB 2001 Approaches to heterogeneity in meta-analysis. Statistics in Medicine 20 3625-3633. (https://doi.org/10.1002/sim.1091)

Petrick JL, Yang B, Altekruse SF, Van Dyke AL, Koshiol J, Graubard BI \& McGlynn KA 2017 Risk factors for intrahepatic and extrahepatic cholangiocarcinoma in the United States: a population-based study in SEER-Medicare. PLoS ONE 12 e0186643. (https://doi.org/10.1371/ journal.pone.0186643)

Pinto M, Soares P \& Ribatti D 2011 Thyroid hormone as a regulator of tumor induced angiogenesis. Cancer Letters 301 119-126. (https:// doi.org/10.1016/j.canlet.2010.11.011)

Resende de Paiva C, Grønhøj C, Feldt-Rasmussen U \& von Buchwald C 2017 Association between Hashimoto's thyroiditis and thyroid cancer in 64,628 patients. Frontiers in Oncology 7 53-53. (https://doi. org/10.3389/fonc.2017.00053)

Rinaldi S, Plummer M, Biessy C, Tsilidis KK, Østergaard JN, Overvad K, Tjønneland A, Halkjær J, Boutron-Ruault MC, Clavel-Chapelon F, et al. 2014 Thyroid-stimulating hormone, thyroglobulin, and thyroid hormones and risk of differentiated thyroid carcinoma: the EPIC study. Journal of the National Cancer Institute 106 dju097. (https://doi. org/10.1093/jnci/dju097)

Sandhu MK, Brezden-Masley C, Lipscombe LL, Zagorski B \& Booth GL 2009 Autoimmune hypothyroidism and breast cancer in the elderly. Breast Cancer Research and Treatment 115 635-641. (https://doi. org/10.1007/s10549-008-0104-4)
Sarfati D, Koczwara B \& Jackson C 2016 The impact of comorbidity on cancer and its treatment. CA: A Cancer Journal for Clinicians 66 337-350. (https://doi.org/10.3322/caac.21342)

Sarlis NJ, Gourgiotis L, Pucino F \& Tolis GJ 2002 Lack of association between Hashimoto thyroiditis and breast cancer: a quantitative research synthesis. Hormones 1 35-41. (https://doi.org/10.14310/ horm.2002.1152)

Shu X, Ji J, Li X, Sundquist J, Sundquist K \& Hemminki K 2010 Cancer risk in patients hospitalised for Graves' disease: a population-based cohort study in Sweden. British Journal of Cancer 102 1397-1399. (https://doi.org/10.1038/sj.bjc.6605624)

Søgaard M, Farkas DK, Ehrenstein V, Jørgensen JOL, Dekkers OM \& Sørensen HT 2016 Hypothyroidism and hyperthyroidism and breast cancer risk: a nationwide cohort study. European Journal of Endocrinology 174 409-414. (https://doi.org/10.1530/EJE-15-0989)

Staniforth JU, Erdirimanne S \& Eslick GD 2016 Thyroid carcinoma in Graves' disease: a meta-analysis. International Journal of Surgery $\mathbf{2 7}$ 118-125. (https://doi.org/10.1016/j.ijsu.2015.11.027)

Talamini R, Franceschi S, Favero A, Negri E, Parazzini F \& La Vecchia C 1997 Selected medical conditions and risk of breast cancer. British Journal of Cancer 75 1699-1703. (https://doi.org/10.1038/ bjc.1997.289)

Thompson SG \& Higgins JP 2002 How should meta-regression analyses be undertaken and interpreted? Statistics in Medicine 21 1559-1573. (https://doi.org/10.1002/sim.1187)

Tosovic A, Bondeson AG, Bondeson L, Ericsson UB, Malm J \& Manjer J 2010 Prospectively measured triiodothyronine levels are positively associated with breast cancer risk in postmenopausal women. Breast Cancer Research 12 R33. (https://doi.org/10.1186/bcr2587)

Tosovic A, Becker C, Bondeson AG, Bondeson L, Ericsson UB, Malm J \& Manjer J 2012 Prospectively measured thyroid hormones and thyroid peroxidase antibodies in relation to breast cancer risk. International Journal of Cancer 131 2126-2133. (https://doi. org/10.1002/ijc.27470)

Tsui KH, Hsieh WC, Lin MH, Chang PL \& Juang HH 2008 Triiodothyronine modulates cell proliferation of human prostatic carcinoma cells by downregulation of the B-cell translocation gene 2. Prostate 68 610-619. (https://doi.org/10.1002/ pros.20725)

Viechtbauer W \& Cheung MWL 2010 Outlier and influence diagnostics for meta-analysis. Research Synthesis Methods 1 112-125. (https://doi. org/10.1002/jrsm.11)

Wells GA, Shea B, O'Connell D, Peterson J, Welch V, Losos M \& Tugwell P 2001 The Newcastle-Ottawa Scale (NOS) for assessing the quality of non randomised studies in meta-analyses. Ottowa, Canada: University of Ottawa. (available at: http://www.ohri.ca/programs/ clinical_epidemiology/oxford.asp)

Welzel TM, Graubard BI, El-Serag HB, Shaib YH, Hsing AW, Davila JA \& McGlynn KA 2007 Risk factors for intrahepatic and extrahepatic cholangiocarcinoma in the United States: a population-based casecontrol study. Clinical Gastroenterology and Hepatology 5 1221-1228. (https://doi.org/10.1016/j.cgh.2007.05.020)

Yeh NC, Chou CW, Weng SF, Yang CY, Yen FC, Lee SY, Wang JJ \& Tien KJ 2013 Hyperthyroidism and thyroid cancer risk: a populationbased cohort study. Experimental and Clinical Endocrinology and Diabetes 121 402-406. (https://doi.org/10.1055/s-0033-1341474)

Received in final form 4 February 2020

Accepted 7 February 2020

Accepted Manuscript published online 10 February 2020 https://erc.bioscientifica.com https://doi.org/10.1530/ERC-19-0417 (c) 2020 Society for Endocrinology Published by Bioscientifica Ltd. Printed in Great Britain 